\title{
Commentary Colloid-induced kidney injury: experimental evidence may help to understand mechanisms
}

\author{
Frédérique Schortgen ${ }^{1}$ and Laurent Brochard ${ }^{1,2,3}$
}

\author{
${ }^{1}$ AP-HP, Groupe Hospitalier Albert Chenevier - Henri Mondor, Réanimation Médicale, F-94000 Créteil, France \\ 2Université Paris 12, Faculté de Médecine, F-94000 Créteil, France \\ 3INSERM, U955, Faculté de Médecine, F-94000 Créteil, France
}

Corresponding author: Frédérique Schortgen, frederique.schortgen@hmn.aphp.fr

Published: 3 April 2009

This article is online at http://ccforum.com/content/13/2/130

(c) 2009 BioMed Central Ltd

See related research by Hüter et al., http://ccforum.com/content/13/1/R23
Critical Care 2009, 13:130 (doi:10.1186/cc7745)

\begin{abstract}
Fluid resuscitation is widely used, and many patients are therefore exposed to plasma volume expanders. Among these, colloids, particularly hydroxyethyl starches, have been shown in recent experiments and clinical studies to induce acute kidney injury. The mechanisms of colloid-induced acute kidney injury remain incompletely elucidated. The risks associated with colloid osmotic pressure elevation in vivo and the high incidence of osmotic nephrosis lesions in experimental models and clinical studies indicate that hydroxyethyl starches can no longer be considered safe.
\end{abstract}

Plasma volume expansion is often required in the operating room, emergency department, or intensive care unit. The safety of plasma volume expanders therefore deserves careful consideration. Low renal perfusion is a major risk factor for acute kidney injury (AKI), and plasma volume expansion is therefore crucial for its prevention. On the contrary, among plasma volume expanders, colloids can induce kidney injury, as shown many years ago [1-5]. Recent experiments and clinical studies have supplied further information on the renal toxicity of some colloids, particularly hydroxyethyl starches (HESs) [6-9].

Colloid-induced AKI with morphological abnormalities of the proximal tubular cells, or osmotic nephrosis, has been reported after the infusion of low-molecular-weight dextran or, more recently, HES. The tubular lesions reflect the accumulation of proximal tubular lysosomes due to pinocytosis of exogenous osmotic solutes (for example, mannitol, sucrose, iodinated contrast media, or colloids) [10]. The tubular cells swell because they contain numerous lysosomes and endocytotic vacuoles. Furthermore, the oncotic force of colloids may induce further renal function impairment by decreasing the renal filtration pressure [3]. The exact mechanisms of colloid-induced AKI remain incompletely elucidated, and controversy exists regarding the relative roles for morphological and functional changes [4].

Because HESs are widely used and AKI is strongly associated with decreased survival, the risk of $A K I$ associated with various HESs needs to be determined. Three generations of HES have been developed over time. Newer HESs have lower molecular weight and lower degree of substitution, two changes that should decrease accumulation and toxicity [11]. Third-generation HESs have molecular weights lower than $200 \mathrm{kDa}$ and degrees of hydroxyl substitution lower than 0.5 , the most common combination being 130/0.4. First-generation and second-generation HESs have been found to induce AKI in heart surgery patients, in braindead organ donors, and in patients with sepsis $[6,7,9,12]$. The most recent randomized controlled trial, which included a large number of patients, showed a higher incidence of AKI with 10\% HES 200/0.5 than with Ringer lactate solution in intensive care unit patients with sepsis [6]. Both the administration of large volumes and high in vitro colloid osmotic pressure (COP) may contribute to renal toxicity. No large randomized controlled trial establishing the safety of third-generation HESs is available.

In the previous issue of Critical Care, Hüter and coworkers report an interesting experiment aimed at improving our understanding of HES-induced AKI [1]. Using hemodilution in a model of isolated kidney perfusion, they assessed the renal effects of one second-generation HES solution and one thirdgeneration HES solution comparative to a crystalloid. Although their model was very different from the clinical situation, and the number of studied animals was limited, morphological studies of the kidneys yielded useful infor-

$\mathrm{AKI}=$ acute kidney injury $\mathrm{COP}=$ colloid osmotic pressure; $\mathrm{HES}=$ hydroxyethyl starch. 
mation. After in vivo hemodilution, creatinine clearance was higher with the crystalloid than with either HES. As expected, the glomerular filtration pressure was much higher with the crystalloid. For a similar mean arterial pressure, the COP was considerably lower after crystalloid infusion and was similarly increased with both HESs. Although the two HESs had different in vitro COP values, their in vivo COP effect was similar. The rapid in vivo degradation of HES 130/0.4 usually results in a high plasma COP, as illustrated here. After isolated kidney perfusion, the plasma COP remained similar in the two HES groups, but creatinine clearance was lower with the second-generation 10\% HES 200/0.5. This result suggests an additional role for a delayed decrease in glomerular filtration, independent of filtration pressure. Morphological examination showed that the lesions of osmotic nephrosis were more severe in the two HES groups, despite the limited volumes infused. Tubular lesions appeared as early as 6 hours after exposure and were associated with greater severity of the interstitial inflammation and tubular dysfunction in the 10\% HES 200/0.5 group.

The results of this experiment have implications for clinical practice. First, the in vivo COP of the fluid used may have an early effect on the glomerular filtration pressure, as recently suggested in patients resuscitated for shock [8]. With polydispersed macromolecules such as HES, the in vivo COP differs from the in vitro COP. Also, third-generation HESs can induce osmotic nephrosis similar to that seen with older compounds, within a few hours of exposure. Recent systematic reviews have alerted clinicians to the renal toxicity of HES [13,14]. In the absence of large randomized controlled trials, doubts about the safety of third-generation HES persist, and the results reported by Hüter and colleagues leave room for concern about the safety of widespread use of third-generation HES. Furthermore, HESs have been reported to induce not only $\mathrm{AKI}$, but also irreversible chronic renal failure $[10,15,16]$.

The question therefore is should HESs or other colloids ever be used for fluid resuscitation? There is no evidence from randomized controlled trials that colloids improve patient outcomes [17]. Thousands of patients included in randomized controlled trials have been safely resuscitated using only crystalloids [17]. Furthermore, the study by Hüter and coworkers shows that colloid toxicity and the risk of colloid-induced AKI can be assessed experimentally before colloids are considered for use in humans.

\section{Competing interests}

The authors declare that they have no competing interests.

\section{References}

1. Hüter L, Simon T, Weinmann L, Schuerholz T, Reinhart K, Wolf G, Amann K, Marx G: Hydroxyethylstarch impairs renal function and induces interstitial proliferation, macrophage infiltration and tubular damage in an isolated renal perfusion model. Crit Care 2009, 13:R23.
2. Janssen CW, Jr: Osmotic nephrosis. A clinical and experimental investigation. Acta Chir Scand 1968, 134:481-487.

3. Moran M, Kapsner C: Acute renal failure associated with elevated plasma oncotic pressure. $N$ Engl J Med 1987, 317:150153.

4. Druml W, Polzleitner D, Laggner AN, Lenz K, Ulrich W: Dextran40 , acute renal failure, and elevated plasma oncotic pressure. N Engl J Med 1988, 318:252-254.

5. Moore FA, McKinley BA, Moore EE: The next generation in shock resuscitation. Lancet 2004, 363:1988-1996.

6. Brunkhorst FM, Engel C, Bloos F, Meier-Hellmann A, Ragaller M, Weiler N, Moerer O, Gruendling M, Oppert M, Grond S, Olthoff D, Jaschinski U, John S, Rossaint R, Welte T, Schaefer M, Kern P, Kuhnt E, Kiehntopf M, Hartog C, Natanson C, Loeffler M, Reinhart $\mathrm{K}$, the German Competence Network S: Intensive insulin therapy and pentastarch resuscitation in severe sepsis. $N$ Engl J Med 2008, 358:125-139.

7. Cittanova ML, Leblanc I, Legendre C, Mouquet C, Riou B, Coriat $P$ : Effect of hydroxyethylstarch in brain-dead kidney donors on renal function in kidney-transplant recipients. Lancet 1996, 348:1620-1622.

8. Schortgen F, Girou E, Deye N, Brochard L: The risk associated with hyperoncotic colloids in patients with shock. Intensive Care Med 2008, 7:7.

9. Schortgen F, Lacherade JC, Bruneel F, Cattaneo I, Hemery F, Lemaire $F$, Brochard $L$ : Effects of hydroxyethylstarch and gelatin on renal function in severe sepsis: a multicentre randomised study. Lancet 2001, 357:911-916.

10. Dickenmann M, Oettl T, Mihatsch MJ: Osmotic nephrosis: acute kidney injury with accumulation of proximal tubular lysosomes due to administration of exogenous solutes. Am J Kidney Dis 2008, 51:491-503.

11. Boldt J, Suttner S: Plasma substitutes. Minerva Anestesiol 2005, 71:741-758.

12. Winkelmayer WC, Glynn RJ, Levin R, Avorn J: Hydroxyethyl starch and change in renal function in patients undergoing coronary artery bypass graft surgery. Kidney Int 2003, 64: 1046-1049.

13. Zarychanski R, Turgeon AF, Fergusson DA, Cook DJ, Hebert $P$, Bagshaw S, Monsour D, Mclntyre L: Renal outcomes following hydroxyethl starch resuscitation: a meta-analysis of randomized trials [abstract]. Intensive Care Med 2008, 34(Suppl 1): A0345.

14. Wiedermann CJ: Systematic review of randomized clinical trials on the use of hydroxyethyl starch for fluid management in sepsis. BMC Emerg Med 2008, 8:1-8.

15. Pillebout E, Nochy D, Hill G, Conti F, Antoine C, Calmus Y, Glotz D: Renal histopathological lesions after orthotopic liver transplantation (OLT). Am J Transplant 2005, 5:1120-1129.

16. Jamal R, Ghannoum M, Naud J-F, Turgeon P-P, Leblanc M: Permanent renal failure induced by pentastarch. NDT Plus 2008, 1:322-325.

17. Perel $P$, Roberts I: Colloids versus crystalloids for fluid resuscitation in critically ill patients. Cochrane Database Syst Rev 2007, 4:CD000567. 